\title{
Yangın Safhalarının HTEA Risk Analizi ile İncelenmesi
}

\author{
Examination of Fire Stages with FMEA Risk Analysis
}

Muharrem Kemal ÖZFIRAT (iD , Pınar MIZRAK ÖZFIRAT

\begin{abstract}
ÖZET
Yangın, katı, sıvı veya gaz halindeki yanıcı maddelerin kontrol dışı yanma olayıdır. Yanıcı maddenin tutuşma sıcaklığına ısıtıldı̆̆ında oksijenle verdiği egzotermik zincirleme reaksiyondur. Yangının safhaları başlangıç , denge ve sıcak tütme safhalarıdır. Çalışmada yangının safhaları HTEA yöntemi ile analiz edilerek kontrol yönetiminin sağlanması açısından değerlendirmeler yapılmış ve önlemler belirtilmiştir. Çalışmanın sonucunda yangının başlangıç safhasında alev dili tehlikesi, dumandaki zehirli gazlar ve yayılma tehlikesi yangında oldukça riskli bulunmuştur.
\end{abstract}

Anahtar Kelimeler: Yangın, Yangın safhaları, Risk analizi, Hata türü ve etkileri analizi (HTEA), Risk yönetimi.

\section{ABSTRACT}

Fire is the uncontrolled burning event of flammable substances in solid, liquid or gaseous state. It is an exothermic chain reaction with oxygen when the flammable substance is heated to the ignition temperature. The stages of the fire are initial, equilibrium and hot smoking phases. In this study, the stages of the fire are analyzed by FMEA method, evaluations are made in terms of control management and precautions are determined. As a result of the study, the hazard of flame tongue in the initial phase of the fire, poisonous gases in the smoke and the hazard of spreading are found to be very risky.

Keywords: Fire, Fire stages, Risk analysis, Failure mode effect analysis (FMEA), Risk management.

Muharrem Kemal ÖZFIRAT | kemal.ozfirat@deu.edu.tr Dokuz Eylül Üniversitesi, Mühendislik Fakültesi, İzmir, Türkiye Dokuz Eylul University, Faculty of Engineering, Izmir, Turkey

Pınar MIZRAK ÖZFIRAT | pinar.ozfirat@cbu.edu.tr Manisa Celal Bayar Üniversitesi, Mühendislik Fakültesi, Manisa, Türkiye Manisa Celal Bayar University, Faculty of Engineering, Manisa, Turkey 


\section{GİRIŞ}

Yangın, katı, sıvı veya gaz formundaki maddelerin kontrol dışı yanma ile ani oluşan ve acil durum önlemleri gerektiren bir olaydır. Yangın için gerekli koşulların meydana geldiği şekle "Yangın Üçgeni" adı verilir. Şekil 1'de gösterildiği gibi yangın üçgeni, oksijen-sıcaklık-yanıcı madde bileşenlerinden oluşur [1-5].

Şekil 1: Yangın Üçgeni [1-5]

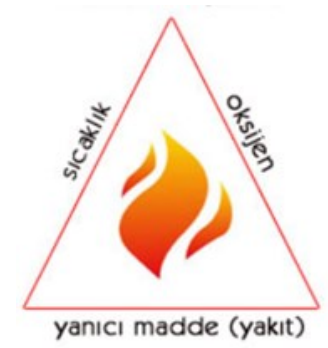

Doğada üç çeşit oksidasyon vardır. Bunlar; yavaş, hızlı ve çok hızlı oksidasyonlardır. Bu oksidayonlara sırasıyla paslanma, yangın ve patlama örnek olarak verilebilir. Yangın, oluştuğu ortamda acil durum meydana getirir. Acil durum; acil eylem gerektirir ve çoğunlukla ciddi tehlike içerip, ani ve tahmin edilemeyen felaket olayıdır. Dolayısıyla yangın olayının müdahalesinde önceden risk analizi ile risk yönetiminin yapılması çok önemlidir. 2012'de yürürlüğe giren 6331 sayılı İş Sağlığı ve Güvenliği Kanununda risk; tehlikeden kaynaklanacak kayıp, yaralanma veya zararlı sonuç meydana gelme olasıllı̆ı olarak tanımlanmıştır. Risk değerlendirmesi ise işyerinde var olan ya da dışarıdan gelebilecek tehlikelerden kaynaklanan risklerin analiz edilmesi ve önlemlerin belirlenmesi amacıyla yapılan çalışmalardır[6].

Yangının safhaları vardır. Bunlar; başlangıç safhası, denge safhası ve sıcak tütme safhasıdır. Başlangıç safhasında oksijen yeterli ama ısı yetersiz olduğundan tam yanma oluşmaz. Örneğin, iş yerinde kapalı bir ortamda yangın başlangıcında oksijen yeterlidir ancak yangının geliştiği nesnenin sıcaklığı düşüktür. Dolayısıyla bu safhada kötü yanma sebebiyle ve sıcak gazlar etkisiyle tavanda biriken bir duman oluşur. Tavanda biriken bu gazlar alev dili (Flame over) şeklinde yanarlar [7]. Denge safhasında sıcaklık artmakta, oksijen yeterli olduğundan ideal yanma olmaktadır. Yükselen sıcak hava yangın çıkan ortamda gezerek tüm yanıı maddeleri tutuşma sıcaklığına getirmektedir. Böylece aniden tüm maddeler yanmaktadır (Flash-over). Sıcak tütme safhasında; ilerleyen yangın oksijenden beslenip oksijeni azalttığından oksijen yetersiz hale gelmektedir. Sıcaklık bu safhada oldukça yüksektir. Ancak, oksijen yetersizliğinden dolayı duman ve duman içerisinde odayı basınçlı bir şekilde yarım yanmış gazlar doldurmaktadır. Kapı veya pencere açıldığında ortama oksijen girmekte ve ortam patlaması (Backdraft) olabilmektedir.

Çalışmada; yangının safhaları Hata Türü ve Etkileri Analizi (HTEA) yöntemi ile analiz edilerek kontrol yönetiminin sağlanması açısından değerlendirmeler yapılmışıır. Çalışmanın sonucunda yangının başlangıç safhasında alev dili tehlikesi (H1), dumandaki gazlar (H3) ve yayılma tehlikesi (H6) yangında oldukça riskli bulunmuştur. Ayrıca, proaktif önlemler; yangın önleme sistemleri ve risk analizleri yangının önlenmesinde dolayısıyla can ve mal kaybının azaltılmasında önemlidir.

\section{YÖNTEM}

Çalışmanın araştırma yöntemi risk analizi ve yönetimidir. Yöntem olarak; öncelikle yangın safhalarındaki tehlike kaynakları belirlenmiş ve HTEA risk analiz yöntemiyle değerlendirmeler yapılmıştır. Elde edilen sonuçlara göre Risk öncelik sayısı (RÖS) değeri yüksek olan hata türlerinin alınan önlemler ile nasıl kontrol edilebileceği açılanmıştır. 


\section{A. HTEA Yöntemi}

HTEA, 1900'lü yılların ortasında bulunmuş olan ve yöntemi iyi düzenlenmiş risk değerlendirme tekniklerinden birisidir. Yabancı literatürde FMEA (Failure Mode and Effect Analysis) olarak yer almaktadır. Yöntemin risk, olasılık ve fark edilebilirlik tablolarının anlaşılır olması olumlu yanıdır. Bu nedenle yöntemle ilgili birçok açıklayıcı yayın, standart ve endüstri çalışmaları vardır [8-11].

HTEA, işletmelerin üretim süreçlerinde planlanan çalışmalarını yerine getiremediği hataların bulunup yönetilmesinde kullanılmaktadır. Aynı zamanda, iş güvenliğinde yapılan hataları belirlemek ve önlemler ile hataların azaltılmasında kullanılan bir tekniktir. Bütün teknoloji ağırlıklı sektörler, uzay sektörü, otomotiv sektörü, kimya endüstrisi ve otomobil sanayinde, maden sektörü hatta inşaat sektörlerinde kullanılmaktadır. Bu metodun yaygın olmasındaki temel sebepler kullanımının kolay olması ve geniş bir teorik bilgiye ihtiyaç duyulmamasıdır.

Günümüzde HTEA; QS 9000, ISO TS 16949, ISO 9001:2000, OHSAS 45001, TS 45001 ve diğer kalite yönetim sistemlerinde bir gereksinim haline gelmiştir [8-11].

HTEA'nın değerlendirme formülü aşağıda verilmekte$\operatorname{dir}[8-11]$

Risk Öncelik Katsayısı (RÖS), Tablo 1, Tablo 2 ve Tablo 3'ten elde edilmiş değerler olan Olasılık (O), Şiddet (Ş) ve Farkedilebilirlik (F) değerlerinin çarpımıyla elde edilir.

$$
\mathrm{RÖS}=\mathrm{O} \times S ̧ \times \mathrm{F}
$$

Tablo 1'de olasılığı çok yüksek kaçınılmaz hata için olasılık değeri “ $1 / 2$ 'den fazla” değeri ile " 10 ” olarak derecelendirilmiştir. Hatanın ortaya çıkma olasılı̆̆ı belirlendikten sonra hata sonucu oluşabilecek şiddet değerleri Tablo 2'de verilmiştir. "Uyarısız gelen tehlikenin” şiddet etkisi “10"
Tablo 1: Hatanın ortaya çıkma olasılığı ve derecesi [8-11]

\begin{tabular}{lcc}
\hline Hatanın oluşma sıklığı & Hatanın olasılığı (0) & Derece \\
\hline Çok yüksek: kaçınılmaz hata & $1 / 2$ 'den fazla & 10 \\
Yüksek: Tekrar tekrar hata & $1 / 3$ & 9 \\
& $1 / 8$ & 8 \\
Orta: Ara sıra olan hata & $1 / 20$ & 7 \\
& $1 / 80$ & 6 \\
Düşük: Nispeten az olan hata & $1 / 400$ & 5 \\
& $1 / 15000$ & 4 \\
Pek az: Olası olmayan hata & $1 / 1000000^{\prime}$ den & 1 \\
\hline
\end{tabular}

iken, şiddet etkisinin "Yok" derecesi ise "1" dir.

Bu yöntemde risk analizine; "Olasılık" ve "Şiddet" tabloları yanında bir de "Fark edilebilirlik" tablosu eklenmiştir. Bu bileşen özellikle eksikliğin ne kadar tehlike yarattığını belirler. Aynı zamanda bir tehlikenin fark edilmemesinin

Tablo 2: Șiddet etkisinin sınıflandırılması [8-11]

\begin{tabular}{llc}
\hline Etki & Şiddetin etkisi (Ş) & Derece \\
\hline $\begin{array}{l}\text { Uyarısız gelen } \\
\text { yüksek tehlike }\end{array}$ & $\begin{array}{l}\text { Felakete yol açabilecek etkiye sahip ve uya- } \\
\text { rısız gelen potansiyel hata }\end{array}$ & 10 \\
\hline $\begin{array}{l}\text { Uyarısız gelen } \\
\text { tehlike }\end{array}$ & $\begin{array}{l}\text { Yüksek hasara ve toplu ölümlere yol açabile- } \\
\text { cek etkiye sahip ve uyarısız gelen potansiyel } \\
\text { hata }\end{array}$ & 9 \\
\hline Çok yüksek & $\begin{array}{l}\text { Sistemin tamamen hasar görmesini sağlayan } \\
\text { yıkıcı etkiye sahip ağır yaralanmalara, 3. } \\
\text { derece yanık, akut ölüm vb. etkiye sahip }\end{array}$ & 8 \\
\hline hata türü
\end{tabular}


Tablo 3: Fark edilebilirlik ve dereceleri [8-11]

\begin{tabular}{|c|c|c|}
\hline Fark edilebilirlik & Fark edilebilirlik Olasılığı (F) & Derece \\
\hline Fark edilemez & $\begin{array}{l}\text { Potansiyel hatanın nedeninin ve takip } \\
\text { eden hatanın fark edilebilirliği mümkün } \\
\text { değil }\end{array}$ & 10 \\
\hline Çok az & $\begin{array}{l}\text { Potansiyel hatanın nedeninin ve takip } \\
\text { eden hatanın fark edilebilirliği çok uzak }\end{array}$ & 9 \\
\hline $\mathrm{Az}$ & $\begin{array}{l}\text { Potansiyel hatanın nedeninin ve takip } \\
\text { eden hatanın fark edilebilirliği uzak }\end{array}$ & 8 \\
\hline Çok düşük & $\begin{array}{l}\text { Potansiyel hatanın nedeninin ve takip } \\
\text { eden hatanın fark edilebilirliği çok düşük }\end{array}$ & 7 \\
\hline Düşük & $\begin{array}{l}\text { Potansiyel hatanın nedeninin ve takip } \\
\text { eden hatanın fark edilebilirliği düşük }\end{array}$ & 6 \\
\hline Orta & $\begin{array}{l}\text { Potansiyel hatanın nedeninin ve takip } \\
\text { eden hatanın fark edilebilirliği orta }\end{array}$ & 5 \\
\hline Yüksek ortalama & $\begin{array}{l}\text { Potansiyel hatanın nedeninin ve takip } \\
\text { eden hatanın fark edilebilirliği yüksek } \\
\text { ortalama }\end{array}$ & 4 \\
\hline Yüksek & $\begin{array}{l}\text { Potansiyel hatanın nedeninin ve takip } \\
\text { eden hatanın fark edilebilirliği yüksek }\end{array}$ & 3 \\
\hline Çok yüksek & $\begin{array}{l}\text { Potansiyel hatanın nedeninin ve takip } \\
\text { eden hatanın fark edilebilirliği çok yük- } \\
\text { sek }\end{array}$ & 2 \\
\hline Hemen hemen k€ & $\begin{array}{l}\text { Potansiyel hatanın nedeninin ve takip } \\
\text { eden hatanın fark edilebilirliği hemen } \\
\text { hemen kesin }\end{array}$ & 1 \\
\hline
\end{tabular}

tehlike seviyesini ne kadar artıracağını gösterir. Tablo 3'te "Fark edilemez hata” "10” olarak derecelendirilmiştir. Böylece RÖS değeri, hatanın olasılı̆̆ı, sonucu ve fark edilebilirliğine yönelik 1 ve 10 arasında derecelenen sayıların çarpılmasıyla elde edilir ve Tablo 4'te verildiği şekilde değerlendirilir. RÖS değeri > "100" ise "mevcut önlemlere ilaveten ek önlemler alınması zorunludur” şeklinde sonuca varılır (Tablo 4).

Tablo 4: Risk Öncelik Sayısı Değerlendirmesi [8-11]

\begin{tabular}{cc}
\hline RÖS Değeri & Önlem \\
\hline RÖS $<40$ & $\begin{array}{c}\text { Mevcut önlemler yeterli, izleme devam } \\
\text { etmelidir. }\end{array}$ \\
$40 \leq$ RÖS $\leq 100$ & $\begin{array}{c}\text { Mevcut önlemlere ek önlemler alınma- } \\
\text { lıdır. }\end{array}$ \\
RÖS $>100$ & $\begin{array}{c}\text { Mevcut önlemlere ilaveten ek önlemler } \\
\text { alınması zorunludur. }\end{array}$ \\
\hline
\end{tabular}

\section{B. Yangın Olayının Safhaları ve Tehlikeleri}

Yangın yerinde mahsur kalan insanları, diğer canlıları ve itfaiyecileri tehdit eden çok çeşitli tehlikeler ve riskler oluşur.

Yangın yerindeki tehlikeler; yangının gelişme hızı, yüksek sıcaklık tehlikesi, yangın üçgeni faktörlerinin yangına etkileri, yangının safhalarındaki tehlikeler, zehirli gazların tehlikesi, patlama tehlikesi, yıkılma tehlikesi ve elektrik tehlikesi olarak sayılabilir [1-5].

Giriş kısmında açıklandığı gibi yangın safhalarında üç aşamadan bahsedilir. Bunlar; başlangıç aşaması, denge aşaması ve sıcak tütme aşamasıdır. (Hangi safhada olduğu belirtilecek). Bu safhadaki tehlike; tavana yakın bölgede her an bir alev dili şeklinde yanabilecek yarım yanmış gazlardan oluşan dumandır. Bu aşamada hava tüplü solunum koruyucu cihazı kullanılmakta ve tabandan ilerleme yapılarak duman etkisinden kaçınılmaktadır.

Duman, başlangıç safhasında önemli bir tehlikedir. Oluşan yangının başlangıç safhasında fark edilebilirliği zordur. Dolayısıyla yangının fark edilememesi, dumandaki gazlar, portatif yangın söndürücünün olmaması, sanayi alanlarında yangın detektörlerinin ve yangın alarmlarının olamaması diğer hatalar olarak sayılabilir.

Denge safhasında, 1sı yeterli, oksijen yeterli, duman az ve hemen hemen ideal yanma gerçekleşmektedir. Bu aşamada yüksek sıcaklık, itfaiyecilerin birden alevlerin ortasında kalması ve ortamda yanan kısımların yıkılması tehlikeleri vardır.

Sıcak tütme aşamasında, ilerleyen yangın oksijeni azalttığından oksijenin yetersiz olması nedeniyle ortamı veya kapalı bölgeyi basınçlı şekilde biriken yarım yanmış gazlar doldurmaktadır. Bu nedenle bu aşamada duman yine çok tehlikelidir. Dumanın içerisindeki yanıcı gazlar patlamaya 
Tablo 5: Yangın Müdahalesi İstatistikleri [12]

\begin{tabular}{|c|c|c|c|c|c|c|}
\hline Yıllar & $\begin{array}{l}\text { Başlangıçta } \\
\text { söndürme }\end{array}$ & $\begin{array}{c}\text { Kısmen yanarak } \\
\text { söndürme }\end{array}$ & $\begin{array}{c}\text { Tamamen yanarak } \\
\text { söndürme }\end{array}$ & $\begin{array}{c}\text { Ölümlü } \\
\text { sayısı }\end{array}$ & Yaralanmalı & $\begin{array}{c}\text { Mali zararı } \\
\text { TL }\end{array}$ \\
\hline \multirow{2}{*}{2015} & 10922 & 289 & 245 & \multirow{2}{*}{12} & \multirow{2}{*}{132} & \multirow{2}{*}{74.514 .435} \\
\hline & $\% 95,34$ & $\% 2,52$ & $\% 2,14$ & & & \\
\hline \multirow{2}{*}{2016} & 13962 & 220 & 176 & \multirow{2}{*}{20} & \multirow{2}{*}{123} & \multirow{2}{*}{88.358 .275} \\
\hline & $\% 97,24$ & $\% 1,53$ & $\% 1,23$ & & & \\
\hline \multirow{2}{*}{2017} & 11679 & 164 & 151 & \multirow{2}{*}{24} & \multirow{2}{*}{157} & \multirow{2}{*}{112.582 .796} \\
\hline & $\% 97,37$ & $\% 1,37$ & $\% 1,26$ & & & \\
\hline \multirow{2}{*}{2018} & 11540 & 194 & 164 & \multirow{2}{*}{14} & \multirow{2}{*}{162} & \multirow{2}{*}{111.697 .435} \\
\hline & $\% 96,99$ & $\% 1,63$ & $\% 1,38$ & & & \\
\hline \multirow{2}{*}{2019} & 10578 & 395 & 172 & \multirow{2}{*}{13} & \multirow{2}{*}{148} & \multirow{2}{*}{174.213 .790} \\
\hline & $\% 94,91$ & $\% 3,55$ & $\% 1,54$ & & & \\
\hline
\end{tabular}

neden olabilir. Ortamda diğer bir tehlike ise yüksek sıcaklik tehlikesidir.

\section{HTEA UYGULAMASI}

Kapalı ortamlarda oluşan yangınların gelişmesinde ve bitmesinde oluşan tehlikeler oldukça büyük tehlikelerdir. Ancak çok farklı yapılarda görülmesi olası yangınların büyümeden önlenmesi için yapıların özelliklerine ve yangın türlerine karşı risk analiz çalışmaları yapılmalıdır. Risk analizinden sonra kabul edilebilir risk seviyelerinin üzerinde bulunan riskler için alınacak önlemler ile olayların önlenmesi sağlanabilir. Bu nedenle yangın safhalarının tehlikelerine yönelik HTEA yöntemi ile risk analiz uygulaması yapılmıştır. Yangın safhalarında oluşan tehlikelere ve yapılan hatalara, sanayide olan olaylar, literatür araştırmaları, yangın raporlamaları ve yangınların istatistiksel sonuçlarıyla karar verilmiştir.

Örneğin İzmir Büyükşehir Belediyesi itfaiye dairesi başkanlığının [12] verdiği tüm istatistikler incelenmiş ve bundan sonraki yangınları önlemek için ne kadar önemli bilgiler verildiği belirlenmiştir (Tablo 5). Tablo 5'te 20152019 yılları arasında verilen istatistikler incelendiğinde bu yıllar arasında arasında yangınların çok büyük kısmının başarıyla başlangıç safhasında söndürüldüğü görülmektedir.

2015-2019 yılları arasında ortalama olarak, yangınların ortalama \%1,51'i sıcak tütme aşamasında yani ortam tamamen yandıktan sonra söndürülmüştür. Yapılan risk analizi ile başarılı sonuçların daha da arttırılması amaçlanmaktadır. Tablo 5'e göre; İzmir'deki yangınların kısmen yanarak söndürmelerde ortalama değeri \%2,12'dir. Bu değerin, yapılacak olan risk analizleri ile başlangıç aşamasında söndürmeye döndürülmesi yangın söndürme başarı oranını daha da artıracaktır. Böylece oluşan can ve mal kaybı azalacaktır. 2015-2019 yılları arasında ortalama mali zarar 112.273.346,2 TL'den ne kadar düşürülürse milli ekonomi için fayda sağlanmış olacaktır. Bu amaçlarla; risk analizine yangın aşamalarındaki tehlikelerin belirlenmesiyle başlanmıştır.

Başlangıç aşamasındaki tehlikeler;

- Alev dili tehlikesi (H1)

- Duman tehlikesi (H2)

- Dumandaki gazlar (H3)

- Alevin fark edilmemesi (H4)

Denge safhasındaki tehlikeler;

- Yüksek sıcaklık tehlikesi (H5)

- Yayılma tehlikesi (H6)

Sıcak tütme safhasındaki tehlikeler;

- Patlama tehlikesi (backdraft) (H7)

olarak belirlenmiştir.

Tablo 6'da önlemsiz durum için bir HTEA yapılmıştır. 
Tablo 6: Önlemsiz durum için HTEA

\begin{tabular}{|c|c|c|c|c|c|}
\hline Hatalar & 0 & Ş & $\mathbf{F}$ & RÖS & Düzeltici Önlem \\
\hline $\mathrm{H} 1$ & 7 & 9 & 8 & 504 & $\begin{array}{l}\text { Tabandan ilerleme ve tavana doğru etken madde ile müdahale } \\
\text { yapmak. Portatif söndürücü ve sprinkler sistem olmalıdır. }\end{array}$ \\
\hline $\mathrm{H} 2$ & 8 & 9 & 6 & 432 & Tabandan ilerleme ve hava tüplü solunum cihazı kullanılmalıdır. \\
\hline H3 & 8 & 9 & 9 & 648 & Hava tüplü solunum cihazı kullanılmalıdır. \\
\hline $\mathrm{H} 4$ & 8 & 7 & 7 & 392 & $\begin{array}{l}\text { Yangın dedektörü, sprinkler sistem olması ve portatif yangın } \\
\text { söndürme cihazı olmalıdır. }\end{array}$ \\
\hline H5 & 8 & 10 & 4 & 320 & Yanmaz elbise kullanılmalı ve ekiple iletişimli ilerlenmelidir. \\
\hline H6 & 7 & 9 & 9 & 567 & Duvarlar su ile soğutulmalıdır. Ekiple iletişimli ilerlenmelidir. \\
\hline $\mathrm{H7}$ & 8 & 9 & 6 & 432 & Kapının bir kısmı kırılmalı ve duman ortamdan çıkarılmalıdır. \\
\hline
\end{tabular}

Sonrasında alınması gerekli önlemler verilmiştir.

Tablo 6'da, H1-H7 hataları RÖS puanları hesaplanmıştır. Bu değerler hesaplanırken literatür verileri, Tablo 1 'de verilen istatistikler, yangın tehlikeleri ve oluşan durumların bilgileri kullanılmıştır. H3 dumandaki gazlar tehlikesi, yangının başlangıç safhasından yangının denge safhasına geçmesine olanak tanıdığı için ve içerdiği gazların tehlikeli etkisiyle 648 puan olarak bulunmuştur. Dumanda özellikle birçok gaz bulunur. Bunlardan en tehlikelisi Karbonmonoksit (CO) gazıdır. CO gazı, hemoglobin ile bağlanmaya $\mathrm{O}_{2}$ 'ye oranla 200-250 kat daha meyillidir. Bu nedenle CO gazı insanı çok hızlı olarak kimyasal boğar yani zehirler. Bunun dışında $\mathrm{CO}_{2}, \mathrm{CH}_{2} \mathrm{O}, \mathrm{HCOOH}$, $\mathrm{C}_{3} \mathrm{H}_{4} \mathrm{O}, \mathrm{COCl}_{2}, \mathrm{HCN}, \mathrm{H}_{2} \mathrm{~S}, \mathrm{HCl}, \mathrm{NH}_{3}$, NO türevleri gibi gazlar duman kütlesinin içinde oldukça tehlikeli gazlardır.

Alev dili tehlikesi (H1), RÖS değeri 504 puan bulunmuştur. RÖS değeri Tablo 4'te verilen değerlere göre 100'den büyük olduğu için “mevcut önlemlere ilaveten ek önlemler alınmak zorundadır” önlemine uygun olarak acilen önlem alınmalıdır. Tablo 6'da verildiği gibi tabandan ilerleme ve tavana doğru etken madde ile müdahale yapılması oldukça önemlidir. Bu tehlike sırasında ortamda portatif söndürücünün olması olayın büyümesini önleyecek en önemli önlemlerden bir tanesidir.

Yayılma tehlikesi (H6) RÖS değeri 567 puan olarak bulunmuştur. RÖS değeri 100'den büyük olduğu için yönteme göre acilen önlem alınmalıdır. Bu nedenle çalışmalar-

Tablo 7: Önlemli durum için HTEA

\begin{tabular}{|c|c|c|c|c|c|}
\hline Hatalar & 0 & Ş & $\mathbf{F}$ & RÖS & Ek Önlem \\
\hline H1 & 4 & 4 & 2 & 32 & $\begin{array}{l}32<40 \text { olduğu için mevcut önlemler yeterli, izleme ve risk analiz- } \\
\text { leri devam etmelidir. }\end{array}$ \\
\hline $\mathrm{H} 2$ & 6 & 6 & 1 & 36 & $\begin{array}{l}36<40 \text { olduğu için mevcut önlemler yeterli, izleme ve risk analiz- } \\
\text { leri devam etmelidir. }\end{array}$ \\
\hline H3 & 6 & 5 & 1 & 30 & $\begin{array}{l}30<40 \text { olduğu için mevcut önlemler yeterli, izleme ve risk analiz- } \\
\text { leri devam etmelidir. }\end{array}$ \\
\hline $\mathrm{H} 4$ & 4 & 4 & 2 & 32 & $\begin{array}{l}32<40 \text { olduğu için mevcut önlemler yeterli, izleme ve risk analiz- } \\
\text { leri devam etmelidir. }\end{array}$ \\
\hline H5 & 5 & 4 & 2 & 40 & $40<=40$ olduğu için mevcut önlemlere ek önlemler alınmalıdır. \\
\hline H6 & 4 & 5 & 3 & 60 & $60>40$ olduğu için mevcut önlemlere ek önlemler alınmalıdır. \\
\hline $\mathrm{H7}$ & 4 & 5 & 4 & 80 & $80>40$ olduğu için mevcut önlemlere ek önlemler alınmalıdır. \\
\hline
\end{tabular}


da, duvarları su ile soğutmak ve ekiple iletişimli ilerlemek RÖS değerinin azalmasını sağlayacaktır.

Tablo 6'da verilen önlemler ile çalışıldığında HTEA tablosu yeniden hazırlanmış ve Tablo 7'de verilmiştir. Alınan önlemler ile çalışmada H1-H4 tehlikeleri 40 puanın altına indirilmiştir. $\mathrm{Bu}$ tehlikelerin RÖS değerleri 40' $\mathrm{n}$ altında olduğu için mevcut önlemler, izleme ve risk analizleri devam etmelidir. $\mathrm{H} 5-\mathrm{H} 7$ tehlikeleri ise 40 puanın üzerinde olduğu için mevcut önlemlere ek olarak önlemler alınmalıdır. Bu tehlikelerin daha kapsamlı analizi yapılarak kontrol edilmesi önerilmektedir. Kapsamlı analizler için çeşitli sektörlere yönelik olarak yapılmış risk analizleri, bulanık risk analizleri ve istatistiksel araştırmalar mevcuttur [13-20].

\section{SONUÇ}

Yapılan çalışmada yangının getirdiği tehlikelerin HTEA yöntemi ile risk analizleri yapılmıştır. Özellikle yangının safhalarında oluşan tehlikeler detaylı olarak ele alınmış ve HTEA analizi ile hem önlemsiz hem de önlemli çalışma için değerlendirme yapılmıştır. Çalışmanın sonucunda yangının başlangıç safhasında alev dili tehlikesi (H1), dumandaki gazlar $(\mathrm{H} 3)$ ve yayılma tehlikesi $(\mathrm{H} 6)$ yangında önlemsiz durumda oldukça riskli bulunmuştur. Önlemli çalışmada ise H1-H5 tehlikeleri kontrol altına alınmış, H5-H7 içinse alınan önlemlere ek olarak önlem alınması şeklinde çalışmalara devam edilmesi önerilmiştir.

YAZAR KaTKıLARI: Yazarların katkıları eşit düzeydedir.

ÇıKar ÇaTışması: Yazarlar herhangi bir çıkar çatışması olmadığını, makalede araşıırma ve yayın etiğine uyulduğunu beyan ederler.

Finansal Destek: Bu çalışmada herhangi bir kişi, kurum veya kuruluştan finansal destek alınmamıştır.
Етік Коміте Onayı: Yazarlar çalışmada insandan anket, mülakat, odak grup çalışması, deney vb. yollarla veri toplanması ve/veya insan ve hayvanların deneysel ya da diğer bilimsel amaçlarla kullanılması faaliyetlerini içermediği için etik kurul onay belgesi gerektirmediğini beyan ederler.

\section{KAYNAKÇA}

[1] 12937 Binaların Yangından Korunması Hakkında Yönetmelik, Resmi Gazete, Sayı: 26735, 19/12/ 2007.

[2] Öner, A. (2009). Yanıcı/parlayıcı sıvı depolanan binalarda yangın güvenliği ve söndürme sistemleri, Uludağ Üniversitesi Müh-Mim. Fak. Dergisi, Cilt 14 (1), 55-66.

[3] Yangın Güvenliği (2020). ELİ yangın söndürme kursu ders notu.

[4] Türker, S. (2005). Yangın ve Güvenlik: Yangından Korunma, Birmat Matbaacllık, İstanbul.

[5] Özkan, İ. (2007). Temel Yangın Teknikleri, Önder Matbaacilık, Ankara.

[6] 6331 Sayılı İşs sağlığı ve Güvenliği Kanunu, Resmi Gazete, Sayl: 28339, 20/06/2012.

[7] İnce, A., (1998). Yangın Yerindeki Tehlikeler, İtfaiye 110 Dergisi, 4(16), 1-15.

[8] Özkılıç, Ö. (2014). İş Sağlığı ve Güvenliği Yönetim Sistemleri ve Risk Değerlendirme Metodolojileri, TİSK Yayınları, Ankara.

[9] Özfirat, P.M. (2014). Bulanık Önceliklendirme Metodu ve Hata Türü ve Etkileri Analizini Birleştiren Yeni Bir Risk Analizi Yöntemi. Gazi Ü. Müh-Mim. Fak. Dergisi, 29(4), 755-768.

[10] Kahraman, Ö., Demirer, A., (2010). Makine Teknolojileri Elektronik Dergisi, 7(1), 53-68.

[11] Wang, Y.M., Chin, K.-S., Poon, G., Yang, J., (2009). Risk Evaluation in Failure Mode and Effect Analysis Using Fuzzy Weighted Geometric Mean, Expert System with Applications, 36, 1-13.

[12] İzmir Büyükşehir Belediyesi, İtfaiye Dairesi Başkanlığ İstatistikleri, Erişim tarihi: 29.10.2020. https:// itfaiye.izmir.bel.tr/tr/istatislik/7/9?

AspxAutoDetectCookieSupport=1.

[13] Kahraman, C., Kaya, İ., \& Şenvar, Ö. (2013). Healthcare failure mode and effects analysis under fuzziness. Human and Ecological Risk Assessment: An International Journal, 19(2), 538-552. 
[14] Kutlu, A. C., \& Ekmekcioglu M. (2012). Fuzzy failure modes and effects analysis by using fuzzy TOPSISbased fuzzy AHP, Expert Systems with Applications 39(1):61-7.

[15] Oturakçı, M., Dağsuyu, C. (2017). Risk Değerlendirmesinde Bulanık Fine-Kinney Yöntemi ve Uygulaması, Karaelmas İş Sağlı̆̆ı ve Güvenliği Dergisi 1 (1):17-25.

[16] Çakmak, A.F., Tatlı, M. (2017). Sağlık Çalışanlarının Güvenlik İklimi Algıları ve Güvenlik Tedbirlerine Uyma Davranışlarının İncelenmesi, Karaelmas İş Sağlığı ve Güvenliği Dergisi 1(1):46-57.

[17] Öney, Ö., Samanlı, S., Özmen, S. (2018). Madencilik Sektöründeki Ölümlü İş Kazalarının Analizi, Karaelmas İş Sağlığı ve Güvenliği Dergisi 2(2):53-61.

[18] Aker, A., Özçelik, T.Ö. (2020). Metal Sektöründe 5x5 Matris ve Fine-Kinney Yöntemi ile Risk Değerlendirmesi, Karaelmas İş Sağlığı ve Güvenliği Dergisi 4(1):65-75.

[19] Özcan, B., Beceren, G. (2020). Demir Çelik Sektöründe İş Kazalarının Çeşitli Faktörlere Göre Analizi, Karaelmas İş Sağlığı ve Güvenliği Dergisi 4(1):1-12.

[20] Özfirat MK, Özkan E, Kahraman B, Şengün B, Yetkin ME. (2017). Integration of risk matrix and event tree analysis: A natural stone plant case, Sadhana 42 (10), 1741-1749. 